\title{
La Comprensión Lectora de textos técnicos del idioma inglés para el aprendizaje mediante el uso de técnicas pedagógicas
}

\begin{abstract}
Web 2.0 as an interactive tool to improve reading comprehension of English texts for university students.
\end{abstract}

Esthela Isabel Colcha Guashpa ${ }^{1}$, Zoila Victoria Herrera Andrade ${ }^{2}$, Rocío de los Ángeles Barragán Murillo $^{3}$, Daniela Fernanda Guano ${ }^{4}$

\section{Resumen}

Al hablar de la comprensión lectora podemos decir que es el proceso mediante el cual un lector construye, a partir de su conocimiento previo, nuevos significados cuando interactúa con el texto, siendo esta la base del entendimiento hacia la interacción del lector con el texto. Este proceso se desarrolla de manera diferente en cada lector, ya que cada individuo tiende a diferentes esquemas y usa sus destrezas y habilidades cuando enfrenta un texto. La experiencia previa es importante, porque esta será determinante en el número de esquemas que posee cada persona, es decir si la experiencia es limitada, también lo harán los esquemas. De ser el caso en que un lector no tiene un esquema definido relacionado con ningún tema o concepto en particular, se puede formar uno nuevo con la información provista, sea esta de los textos utilizados para el aprendizaje del idioma inglés, siendo su texto entendido de varias maneras. lo cual implica formulación de juicios sobre valores presentados en un texto o inferencial en donde se comprende la lectura es decir se entiende lo que se quiere decir. De esta forma, En este documento se revisarán varios términos relacionados con la temática principal entregando una mayor visión al lector para su conocimiento.

Palabras Claves: Comprensión, Lectura, Textos Técnicos, Idioma Inglés, Aprendizaje, Técnicas Pedagógicas.

\footnotetext{
${ }^{1}$ Escuela Superior Politécnica de Chimborazo, Chimborazo, Ecuador, e_colcha@espoch.edu.ec

${ }^{2}$ Escuela Superior Politécnica de Chimborazo, Chimborazo, Ecuador, zoila.herrera@espoch.edu.ec

${ }^{3}$ Escuela Superior Politécnica de Chimborazo, Chimborazo, Ecuador, robarragan@espoch.edu.ec

${ }^{4}$ Escuela Superior Politécnica de Chimborazo, Chimborazo, Ecuador, daniela.guano@espoch.edu.ec
} 


\begin{abstract}
When talking about reading comprehension, we can say that it is the process by which a reader builds new meanings from his/her previous knowledge when interacting with the text, this being the basis of the understanding towards the interaction of the reader with the text. This process is developed differently in each reader, since each individual tends to use different schemes and skills and abilities when facing a text. Previous experience is important because this will be decisive in the number of schemes that each person has, that is, if the experience is limited, so will the schemes. If it is the case in which a reader does not have a defined scheme related to any particular topic or concept, a new one can be formed with the information provided from the texts used for learning the English language, and the text is understood in several ways, which implies the formulation of judgments about values presented in a text or inferential where reading is understood, that is, what is meant. Thus, in this work several terms related to the main theme will be reviewed, giving the reader a better vision for his/her knowledge.
\end{abstract}

Keywords: Comprehension, Reading, Technical texts, English Language, Learning, Pedagogical techniques

\title{
Introducción
}

La importancia que en el contexto actual en la globalización con el dominio del idioma ingles y su aprendizaje es indiscutible, el hecho de que cada día más personas se comunican en esta lengua ha establecido a nivel mundial como la lengua franca en las relaciones internacionales (Crystal, 2006). En vista del crecimiento de este fenómeno muchos países en la actualidad se encuentran reformando sus políticas educativas en función de abrir un espacio para la enseñanza de este idioma desde sus primeros niveles de educación.

Según Paz (2014) el idioma inglés continúa conquistando terreno y es más empleado en las distintas áreas del conocimiento y del desarrollo humano. En consecuencia, este lenguaje se ha convertido en el idioma global de comunicación, por lo cual se hace tan necesario su dominio.

El hombre como ser social necesita comunicarse y el lenguaje es sin duda la herramienta más importante en la comunicación humana. Sin embargo, debido a la variedad de idiomas en ocasiones se hace imposible el entendimiento entre los hablantes. Para superar esta inconveniencia, el fenómeno de una tercera lengua como puente de comunicación, adquirida por interlocutores que no comparten el mismo lenguaje ha estado siempre presente. Es así como desde la segunda mitad del siglo XX el inglés se ha implantado progresivamente como la lengua universal.

Así mismo la comprensión de textos escritos en inglés es una competencia de gran importancia dentro del proceso de formación de los estudiantes, siendo la lectura una de las habilidades más complejas desarrolladas por el hombre y que sin duda alguna lo enriquece tanto profesional como espiritualmente; el desarrollo de la capacidad lectora es un factor muy relevante en la formación de profesionales que deben estar en constante adquisición de conocimiento y 
actualización de información ya que en su gran mayoría la bibliografía especializada está en el idioma inglés.

...en la actualidad el manejo de un segundo idioma, como es el inglés, pasó de ser un valor agregado a constituirse en una competencia lingüística que requiere desarrollar el individuo para integrarse con efectividad y eficacia a la nueva concepción de mundo, definida por la UNESCO como mundialización...impactada por la evidente apertura de mercados y el desarrollo tecnológico producto de la globalización. (2010, p. 64).

El presente documento tiene como objetivo principal reunir la información y explicar la función que desempeña la comprensión lectora de textos de inglés para el aprendizaje mediante el uso de técnicas pedagógicas y mejorar esta destreza en los estudiantes para un desarrollo eficiente en su profesionalización y desempeño laboral.

\section{Comprensión}

La palabra comprensión según Emily Sigmund (2002) "Es un proceso de creación mental por el que, partiendo de ciertos datos aportados por un emisor, el receptor crea una imagen del mensaje que se le quiere transmitir. ... Por el contrario, es un proceso que exige por parte del receptor tanta o más actividad que el proceso de expresión. Para ello es necesario dar un significado a los datos que recibimos. Cuando utilizamos el término "datos" nos estamos refiriendo a cualquier información que pueda ser utilizada para llegar a comprender un mensaje. Los datos pueden ser de diferente tipo: palabras, conceptos, relaciones, implicaciones, formatos, estructuras, pueden ser lingüísticos, culturales, sociales, etc.

Según la WordReference (diccionario online): la comprensión es "entender, alcanzar, ser capaz de conocer una cosa", es decir la acción de comprender y a la facultad para entender y penetrar las cosas.

Según Rojas J, (2009), "la comprensión es el proceso de elaborar el significado por la vía de aprender las ideas relevantes".

El proceso de comprensión, contrariamente a lo que habitualmente se cree, no es un proceso pasivo. Por el contrario, es un proceso que exige por parte del receptor tanta o más actividad que el proceso de expresión. Básicamente, podríamos decir que el proceso de comprensión consiste en aislar, identificar y unir de forma coherente unos datos externos con los datos de que disponemos. Siendo este proceso el mismo en todos los casos aunque variarán los medios y los datos que tendremos que utilizar para llevarlo a cabo.

Queda claro que, si bien la labor que tenemos que realizar para comprender en cada una de las situaciones es la misma, la diferencia estribará en los medios y los datos que tendremos que manipular para poder llegar a hacerlo.

Es importante resaltar la necesidad que tiene el ser humano de comprender y por lo tanto de contar con una hipótesis sobre cualquier acontecimiento. Ante cualquier mensaje o situación 
realizamos una interpretación, la más adecuada y acorde posible a los datos disponibles en ese momento. Esto no quiere decir que sea la "correcta" pero si es suficiente para saciar nuestra necesidad de interpretar la realidad que nos rodea. Es inevitable e imposible no realizar interpretaciones. Todo es interpretado, aunque las interpretaciones estén continuamente variando y completándose. El proceso de creación de interpretaciones es la mayoría de las veces inconsciente, aunque a veces pueda ser controlado conscientemente. La necesidad de realizar el proceso conscientemente es mayor cuando aprendemos una segunda lengua ya que algunos de los procesos que realizamos en nuestra primera lengua se ven anulados cuando los tenemos que llevar a cabo en la segunda. (Araníbar Escarcha, 2018)

\section{Habilidades de comprensión}

Desde esta perspectiva, las habilidades linguiísticas son entendidas como las aptitudes que permiten comunicarnos a través del saber: escuchar, hablar, leer y escribir.

El escuchar es necesario y sirve para oír, comprender y entender las ideas de lo que nos dicen y lo que los otros quieren decirnos; el hablar, sirve para emitir, expresar nuestras ideas, sentimientos e inquietudes a través de la palabra.

Por su parte la habilidad de la lectura, sirve para comprender; pues el lector debe decodificar los mensajes, interpretarlas y comprenderlos; mientras que la habilidad escribir, permite expresar a través de ideas o símbolos, de acuerdo a la cultura para ser comprendidos por otros.

De allí que al relacionarnos a la enseñanza - aprendizaje del idioma inglés se puede inferir que a través de los años, muchos métodos y enfoques para la enseñanza de este idioma han surgido y muchos han quedado en la historia debido a que los resultados obtenidos no han sido los más favorables. En el caso de la enseñanza en la Escuela Superior Politécnica de Chimborazo no ha sido diferente.

Durante las pasadas dos décadas la metodología de enseñanza de las lenguas extranjeras ha estado caracterizada por un claro cambio de enfoque: de la enseñanza centrada en el profesor, en los contenidos y en el método se ha pasado a la enseñanza centrada en el alumno (en sus intereses y necesidades). Desde esta perspectiva, la enseñanza centrada en el alumno, el profesor debe detectar las falencias y/o necesidades de los estudiantes. (Quintanilla \& Ferreira Cabrera, 2010)

Algunas de las mayores dificultades en relación con el aprendizaje de lenguas son: la poca exposición que tienen los alumnos a la lengua meta, el excesivo trabajo en las formas gramaticales y el predominio de las habilidades lingüísticas de comprensión oral y escrita en el trabajo en el aula, lo que por consiguiente circunscribe al estudiante a un rol más bien receptivo.

A partir de este rol receptivo, el estudiante utiliza la lengua, de forma oral o escrita, en contextos reducidos y poco significativos. De allí que se puede apreciar que el exceso de la enseñanza de formas gramaticales en forma aislada resultaba en conocimiento de las estructuras lingüísticas 
de la lengua pero en una producción deficiente de la misma. Como respuesta a la necesidad de una metodología que lograra tanto la fluidez como la producción correcta de segundas lenguas y de lenguas extranjeras.

\section{Condicionantes para la comprensión lectora}

Para Solís (2015) la comprensión lectora se define como el proceso por medio del cual un lector construye, a partir de su conocimiento previo, nuevos significados al interactuar con el texto. Esto es el fundamento de la comprensión: la interacción del lector con el texto. Dicho proceso, se desarrolla de forma distinta en cada lector, ya que cada individuo desarrolla esquemas diferentes y utiliza distintas habilidades y destrezas al momento de enfrentarse a un texto.

En el caso que el lector no posea un esquema en relación con algún tema o concepto, puede formarse uno nuevo de acuerdo a la información proporcionada. De esta manera, a medida que el lector elabora nuevos conocimientos y los relaciona con la información que ha almacenado, los esquemas se amplían. (Icarito, 2012)

Solís (2015) manifiesta que mientras más sea el conocimiento previo del lector, más probabilidades tiene de entender las palabras relevantes, realizar las inferencias correctas durante la lectura y elaborar correctamente los modelos de significado. En este contexto, se incorporan las tecnologías de información y comunicación a través del uso de páginas de internet, correo electrónico y Weblog, apoyados en la metodología CALL (computer-assisted language learning), específicamente $\mathrm{CMC}$, la cual señala que el uso de la comunicación mediada por computadores puede favorecer el desarrollo de las habilidades comunicativas. (Quintanilla \& Ferreira Cabrera, 2010).

Su objetivo es mejorar el aprendizaje en aquellos que aprenden un idioma a través de medios computacionales, permitiendo que el aprendiz desarrolle, expanda y refine sus habilidades comunicacionales en una nueva lengua.

\section{Características del proceso lector}

Sobre el proceso lector, Thorndike (1917) dice:

"Understanding a paragraph is like solving a problem in mathematics. It consists in selecting the right elements of the situation and putting them together in the right relations, and also the right amount of weight or influence or force for each. The mind is assailed as it were by every word in the paragraph. It must select, repress, soften, emphasize, correlate and organize, all under the influence of the right mental set or purpose or demand.” (p. 329)

Bravo (2010) menciona tres subprocesos de la lectura y estos son:

- Antes de la lectura: responde a tres cuestiones: objetivos de la lectura, activación de conocimientos previos, formulación de hipótesis y predicciones sobre el texto. Se determina el propósito de la lectura. La comprensión mejora cuando el estudiante 
reflexiona o discute lo que sabe del tema antes de estudiarlo. Activar el conocimiento previo es una parte importante de la lectura.

- Durante la lectura: se refiere a la interacción con el texto. En esta etapa el alumno requiere de estrategias de control puesto que él controla su propio aprendizaje. En esta etapa ocurren los siguientes procesos: leer de manera secuencial, leer nuevamente algunas partes, tomar apuntes, revisar y adaptar predicciones, conectar el conocimiento con hacer inferencias, parafrasear y resumir pasajes, responder y evaluar el texto.

- Después de la lectura: se comprueba si los conocimientos previos han sido modificados. Durante esta etapa se encuentran los siguientes procesos: realizar una relectura selectiva, reflexionar hacer resúmenes, pensar en cómo la nueva información se puede usar en el futuro.

- Este proceso se usa para que los estudiantes activen su conocimiento previo, por el cual se crea un esquema mental al cual se puede agregar un nuevo texto, nuevos términos, nuevas ideas, etc. Este esquema empieza antes de empezar a leer, se refuerza a media que los estudiantes interactúan con el texto durante la lectura y se refleja después de la lectura cuando los estudiantes incorporan lo que han leído a su conocimiento.

\section{Lectura}

Arrieta de Meza y otros (2008) señalan que:

"La lectura es un proceso perceptivo, lingüístico y cognitivo que comienza en un nivel perceptivo y termina en un nivel conceptual. Una buena decodificación lectora es previa a la compresión, la cual puede concebirse como el entendimiento del significado de un texto y la intencionalidad del autor". (p. 39)

Por su parte, en el Diccionario Panhispánico (2004) se encuentra la siguiente definición: "Pasar la vista por (un texto escrito) para descifrarlo y comprender su significado".

Ramos y Yanchaliquin (2015) sobre la lectura manifiestan "La lectura es una actividad absolutamente humana, que permite, gracias a su realización y puesta en práctica, por ejemplo y entre otras cosas, interpretar una poesía, un cuento, una novela, eso en cuanto a lo estrictamente literario, pero también a la lectura le deberemos la posibilidad de interpretar señas, movimientos del cuerpo, dar o recibir enseñanza". (p. 16)

Brasell y Rasinsky (2008) se refieren a la lectura en la que establecen que es la habilidad de comprender un texto escrito. Comprensión es el punto central de la definición de leer. Por lo tanto, la comprensión lectora. Comprender es extraer ideas usando la mente y esto requiere una acción por parte del lector; esta acción requiere el conocimiento previo del lector sobre un determinado tema y el texto en sí para crear un significado. A su vez Harris and Hodges (1995) dicen que es la construcción del significado de una comunicación escrita por medio del intercambio holístico de ideas entre receptor y mensaje. 
La lectura es una destreza multifacética y compleja y siempre ha sido de constante revisión el cómo enseñar a leer, especialmente con el auge del Internet. Diferentes estrategias de lectura se requieren cuando se trata de textos electrónicos. La forma del texto en si ha cambiado, con los nuevos géneros de texto que han aparecido, por ejemplo email, chat, blogs, etc., así como nuevas combinaciones de texto e imagen. Todos estos nuevos textos requieren nuevas destrezas.

Los estudiantes necesitan poder leer en inglés para tener éxito en sus clases y para poder desenvolverse en un mundo literario globalizado. Muchos expertos manifiestan que el proceso del desarrollo del idioma puede ser mucho más efectivo si el estudiante lee el material en un nivel acorde y si recibe ayuda con el idioma mientras lee.

\section{Componentes de la lectura}

Se puede mencionar 5 componentes de la lectura:

Conocimiento fonético. - se refiere al entendimiento sobre como las palabras están compuestas de unidades separadas de sonidos que se unen cuando las palabras se pronuncian. Se puede entender como la habilidad de escuchar y producir sonidos separados en palabras, que al dividir o segmentar palabras en sonidos, unir sonidos separados en palabras y reconocer palabras que suenas parecidas o diferentes. Los expertos definen como la habilidad de enfocarse y manipular los fonemas cuando las palabras se dicen/pronuncian. Este conocimiento fonético es extremadamente importante cuando se aprende a leer en idiomas que se basan en el alfabeto.

Fonética elemental. - Entender la fonética implica el conocimiento sobre cómo se creó el lenguaje escrito. El lenguaje hablado existió mucho antes del escrito. Cuando las personas inventaron las letras de un alfabeto para representar sonidos del lenguaje hablado, establecieron reglas para diferenciar la ortografía entre palabras. Las reglas que se inventaron para establecer consistencia en los sonidos del lenguaje, se conocen ahora como reglas de fonética. Por lo tanto, se denomina a la fonética como un conjunto de reglas que definen la relación entre letras en la ortografía de palabras y sonidos del lenguaje hablado.

Fluidez. - se considera antiguamente como el reconocimiento rápido de palabras que libera a espacio en la memoria del lector para usarla en la comprensión del mensaje del texto. Es decir, los lectores rápidos necesitan esforzarse menos en el reconocimiento de palabras y por lo tanto tienen más disponibilidad para la comprensión.

Estudios posteriores sobre la fluidez dicen que involucra agrupar palabras dentro de una oración en una frase lo que hace que sea fácil de comprender. Agrupar frases en oraciones que tengan significado y leer con expresión ayuda a que el lector entienda el texto haciendo que lo que se lee se parezca al lenguaje hablado.

Ahora se entiende que la fluencia es el reconocimiento de palabras en un texto rápidamente y eficazmente y el uso de frases y énfasis de modo que lo que se lee suene como el lenguaje hablado. La fluidez está estrechamente relacionada con la comprensión. En el proceso lector 
intervienen dos tareas cognitivas básicas: el lector debe reconocer las palabras impresas (decodificación) y dar significado a las palabras reconocidas (comprensión). Estos requieren a su vez, recursos cognitivos, los mismos que en cualquier momento se ven restringidos por los límites de la memoria. Si el reconocimiento de palabras es difícil, los recursos cognitivos pueden ser usados en la decodificación, dejando poco para la interpretación. En consecuencia, el lector que no es fluido, tiene problemas en el proceso de reconocimiento y usa demasiados recursos que son útiles para la comprensión.

Vocabulario. - hace referencia a palabras que se necesitan conocer para comunicarse con otras personas. El vocabulario es importante para el reconocimiento de palabras. El vocabulario también juega un papel importante en la comprensión.

Comprensión. - se refiere a dar significado conectando lo que se ha leído con los conocimientos del lector y pensar en toda esta información hasta que se entienda.

\section{Las estrategias de comprensión}

- Uso del conocimiento previo

- Preguntas y respuestas

- Monitoreo de la comprensión

- Aprendizaje cooperativo

- Uso de organizadores gráficos y semánticos

- Resumen (A Closer Look at the Five Essential Components of Effective Reading Instruction)

Un buen lector debe hacer uso de estrategias y ser consciente de su propio ritmo de lectura. El docente tendrá que hacer el mejor uso de estos componentes para potenciar y corregir errores en sus estudiantes de modo que mejoren el nivel de comprensión.

\section{Tipos de Lectura}

Lectura de comprensión: Es una lectura realizada con el fin de comprender relacionando el significado con el significado codificado por el escritor del texto. Es el acto de entender lo que se está leyendo.

Lectura Crítica: Requiere una actividad intelectual en la cual el lector construirá nuevos conocimientos que sean de valor para cada lector. El texto que se lee, es discutido en forma razonada y sistemática. A través de esta tipo de lectura, el lector está en capacidad de aceptar o rechazar lo escrito por el escritor.

Lectura Creativa: Este tipo de lectura promueve el desarrollo de la creatividad permitiendo trascender al texto. Se hace uso de la imaginación. Es importante buscar soluciones alternativas a las interrogantes que presenta el texto. 
Lectura Eficiente: Es una actividad mental que parte de elementos físicos que normalmente dificultan la velocidad de la lectura y la comprensión. Es necesario la constante ejercitación, habilidades visuales, aprehensión ocular de lo impreso, así como técnicas que aumenten la comprensión e interpretación de lo leído. (Cerda Muñoz, 2007)

\section{Niveles de la lectura}

Pineda y Lemus (2005) mencionan los siguientes niveles de lectura:

- Nivel literal. - El lector entiende lo que se encuentra en texto sin interpretarlo. Se fundamenta en seis procesos básicos del pensamiento: observación, comparación, relajación, clasificación, ordenamiento y clasificación por jerarquía.

- Nivel inferencial. - El lector debe obtener información a partir de la lectura y llegar a sus propias conclusiones. Se hace uso de palabras claves. Son las relaciones y asociaciones que establece el lector con los diferentes significados del texto y esto causa la construcción de relaciones de implicación, temporalización, especialización, inclusión, exclusión, agrupación, etc., que se encuentran presentes en el proceso del pensamiento y del texto. (Sánchez Ortega \& Osorio Osorio, 2006)

- Nivel analógico. - El lector debe tener la capacidad de relacionar lo leído con anterioridad con nuevas lecturas. Estos tres niveles conducen a una lectura crítica.

\section{La lectura como proceso transaccional}

Crespo (2004) afirma que la lectura va más allá como proceso transaccional. Implica la relación existente entre lector y texto. En la lectura confluyen de manera temporal el lector y el texto. El texto adquiere mayor significado puesto que se comprende de mejor manera los esquemas mismos del lector y texto. Las personas a pesar de ser de una misma cultura comprenderán un mismo texto de diferente manera. Por lo tanto, la interpretación del texto es importante puesto que forma parte de su significado. Esta teoría atiende la individualidad del lector, su forma de ver el mundo y la multiplicidad de un texto. El estudiante no siempre entenderá el texto como lo hace su maestro. Es por eso, que aquí el estudiante cobra protagonismo que debe ser respetado por el docente.

Teoría proveniente de la Literatura y desarrollada por Louise Rosenblatt en 1978 debido a que el término transacción acuñaba la doble y recíproca relación entre el cognoscente y lo conocido. Esta relación enfatiza el círculo dinámico, fluido, reciprocidad en el tiempo, interfusión del texto y lector del significado del texto sea este científico o literario. A diferencia de la lectura como proceso interactivo, el significado dependerá de las transacciones que se den entre texto y lector. Los lectores de una misma cultura y que leen un mismo texto crearan textos similares en sus mentes, pero con significados diferentes. (Araníbar Escarcha) 
Según esta teoría, la comprensión depende del texto-emisor, unicidad del lector -receptor y su momento personal y vivencial, contexto temporal, histórico y cultural en el que el texto está siendo leído. En el encuentro entre texto y lector, se produce una comunicación única que supera al texto. (Blanco Iglesias, 2007)

\section{Textos técnicos}

There can be no denying the fact that the larger part of human communication in our era of scientific and technological progress is concerned with science and technology. The means of communicating in these spheres of life and work are LSP. (Hoffman, 1985: 3)

Para hablar de textos técnicos es necesario primero establecer que es un lenguaje de especialidad. Cabré (1993) manifiesta que el lenguaje de especialidad es un conjunto de posibilidades determinadas por los elementos que intervienen en cada acto de comunicación son los interlocutores (emisor - destinatario), Circunstancias comunicativas, y; Función.

Los lenguajes de especialidad son códigos de carácter linguiístico, diferenciados del lenguaje general que constan de reglas y unidades específicas. Es una simple variante del lenguaje natural. Son subconjuntos fundamentalmente pragmáticos. La función comunicativa está por encima de otras funciones. Los lenguajes de especialidad son producciones lingüísticas sobre parcelas específicas del conocimiento.

Un texto especializado (técnico) se manifiesta a través de producciones lingüísticas. Los documentos especializados se caracterizan por:

- Constituyen líneas cerradas

- Son representaciones de actos de lenguaje diversos

- No son espontáneos

- Se dan exclusivamente en nivel escrito

Estos se definen por su desviación respecto al estándar de comunicación puesto que no es de dominio público lo que lo separa de un documento en lengua general. Un texto es especializado cuando respecta la conceptualización propia de un ámbito determinado por los especialistas y compartido por la comunidad experta.

La temática, los recursos lingüísticos y la especificidad separan un documento técnico de un general. Tienen un formato específico, terminología, sintaxis y fraseología. Méndez (2011) menciona que los textos técnicos y científicos contienen una gran cantidad de información, siendo la mayoría hechos. Los lectores de tales textos deben ser capaces no sólo de extraer información sino también de entender el material completamente; para ello será necesario realizar una lectura detallada. 
Leer un texto técnico y entenderlo podría no ser una tarea sencilla si se lo realiza en un idioma extranjero. Los estudiantes tienen que leer textos en inglés ya que la mayor parte del conocimiento técnico y científico está en este idioma. El problema puede ser aliviado si se da a los estudiantes las técnicas que le permitan manejarlas con diferentes textos sobre varios temas. Estas técnicas incluyen la clase de conocimiento y técnicas necesarias para manejar, entre otros, los siguientes problemas al leer en inglés son el Interpretar el significado de las palabras, Comprender oraciones, Comprender párrafos e Interpretar ilustraciones. (Méndez c., 2011)

\section{Idioma Inglés}

Quezada (2005) afirma que el auge del inglés en este siglo ha sido considerable. Esto se debe a las tendencias globales en tecnología, demografía y economía. Dado que el inglés es uno de los idiomas más usados alrededor del mundo, muchas veces se hace referencia a él como el "idioma global", la "lengua franca" de la era moderna. Cientos de millones de personas están aprendiendo inglés, el idioma del planeta para el comercio, la tecnología y, cada vez más, para el poder.

El idioma ingles ha adquirido el status de lingua franca debido al colonialismo Británico y el americanismo particularmente de los avances y dominio de la post guerra Estados Unidos en economía, tecnología y ciencia, educción e incluso entretenimiento. Las personas se comunican con sus socios de negocios en inglés, escuchan música pop anglófona, miran novelas o películas americanas, leen artículos, navegan en internet el cual es casi $80 \%$ en inglés. (Luo, 2007)

A pesar de que el idioma inglés no cuenta con el mayor número de hablantes, se le considera como lingua franca que quiere decir que es un idioma ampliamente adoptado para la comunicación entre dos personas cuyo idioma nativo no es el inglés y que lo están usando como segundo idioma. Al igual que el latín en Europa en la edad media, el inglés es el idioma principal de comunicación internacional.

Quezada (2005) de igual forma dice que ahora estudiar inglés es obligatorio sobre todo a nivel universitario y laboral en todo el mundo. El idioma ingles es importante en cualquier aspecto de la vida personal o profesional. Es el idioma que se usa en los negocios y el turismo.

\section{Importancia del idioma inglés}

Muchas asignaturas académicas alrededor del mundo se imparten en inglés. Muchas veces es el idioma usado en conferencias y artículos científicos sobre distintas áreas como ingeniería o medicina. El internet en sus primeros de aparición uso como medio principal el idioma inglés. En occidente, el idioma ingles es el idioma que predomina en la cultura popular. Por ejemplo, la música pop en ingles se escucha en todo el mundo, es así que las personas pueden cantar estas aun cuando no es su idioma nativo. Muchas personas prefieren ver películas en inglés con subtítulos. 
El idioma inglés con un léxico muy rico en el cual se superponen palabras de origen germánico y sinónimos latinos, complicada fonética, ortografía y preposiciones. Es el idioma menos adecuado para usarlo en comunicación. Por lo general, en ingles se anteponen al sustantivo dos o más adjetivos, característica propia del lenguaje científico que puede generar imprecisión en la lectura. Otra característica de este tipo de textos, es sustantivos con cinco o más calificativos que le preceden.

El idioma inglés es predominante en comunicación y a nivel científico no porque los otros idiomas sean más primitivos o imperfectos, sino porque los hablantes lo imponen en un momento histórico para distintas actividades como el comercio, política, cultura, etc. El idioma ingles es predominante en la comunicación científica. Una de las causas del predominio del idioma ingles sobre las demás lenguas es el predominio científico y económico de los Estados Unidos y el otro es que la publicación de trabajos de autores no anglohablantes en inglés en revistas internacionales y nacionales. A partir de 1985, en occidente se adopta que los trabajos de investigación de calidad deberían estar escritos en inglés. (Navarro F. A., 2001)

\section{Inglés con fines específicos}

En las instituciones educativas del mundo, los estudiantes aprenden el idioma para poder comunicarse y entender diferentes textos cuando son profesionales. El inglés general se enseña cuando los docentes no saben cómo, por qué o cuando los estudiantes necesitaran usar el idioma en su futuro. Por esa razón, se les enseña un inglés lo más general posible. Por el contrario, los estudiantes que estudian inglés con fines específicos (ESP, por sus siglas en inglés) tienen un propósito. Podría ser que estudien ESP para poder ingresar a una universidad, en cuyo caso se estaría hablando de inglés con fines académicos. Se enfoca en escribir ensayos, tomar notas de conferencias, etc. En caso de que el estudiante tenga como objetivo ser científico o ingeniero, tendrá que aprender inglés para la ciencia y la tecnología en cuyo caso el docente tendrá que hacer que mejoren sus destrezas para investigar o diseñar manuales entre otras cosas.

Los artículos científicos emplean voces pasivas. Los ensayos académicos requieren un estilo de discurso y expresiones particulares que no se usan una comunicación social normal. El lenguaje usado en control de tráfico aéreo emplea vocabulario específico, los empleados de la industria del turismo necesitan vocabulario específico y los tipos de interacciones de lenguaje como por ejemplo, lidiar con clientes insatisfechos. (Harmer, 2001)

Caballero (1993) sobre Ingles con fines específicos menciona lo siguiente:

“...se utiliza para referirse a la enseñanza del inglés que tiene un propósito: netamente utilitario. Es decir, su utilidad con relación a una necesidad ocupacional, por ejemplo, para operadores de teléfonos internacionales, pilotos de líneas aéreas, etc...; para programas vocacionales de entretenimiento, por ejemplo, para personal de hotelería y provisión de alimentos, ramas técnicas(2); o también para algún estudio académico o profesional, por ejemplo, ingeniería, medicina, leyes.” (p. 1) 
Revilla (2003) afirma que en ESP se combina lo disciplinar y la lingüística, puesto que a través de la lengua el estudiante adquiere conocimientos y a través de estos conocimientos desarrolla destrezas en inglés. Es un enfoque interdisciplinar e instrumental. Un curso de ESP tiene que tomar en cuenta tres aspectos fundamentales: a) linguiística, b) pedagogía y c) temáticadisciplinar del alumno siendo el enfoque del análisis del discurso el mejor que contempla estos aspectos.

Una de las características del ESP, es limitar el desarrollo de las destrezas de inglés, puesto que según el propósito se requerirá una destreza más que otra. Es decir, podría solo requerirse desarrollar la destreza de escribir y dejar a un lado las otras. Esta restricción podría ser útil en casos de requerir desarrollar la destreza en corto tiempo. Una desventaja es que después en periodos de largo aprendizaje, el estudiante pierde la motivación. Otra característica es la especificidad, encontrar material específico puede ser un muy restringido en cursos de ESP. (Vidal, 2005)

Considerando lo expuesto anteriormente, los estudiantes de la Ingeniería Industrial al momento de encontrarse en un lugar de trabajo deben estar en capacidad de hacer uso del idioma inglés como parte de su actividad profesional.

\section{Metodología para el proceso de enseñanza aprendizaje del idioma inglés}

Sobre los métodos de enseñanza de inglés Liu (2007) manifiesta que se componen en:

El método de traducción gramática. - denominado también como método clásico, ha sido usado por muchos años. Se pensaba que si los estudiantes conocían la gramática podrían hablar y escribir correctamente en su idioma nativo. El propósito fundamental es poder leer literatura escrita en idioma objetivo. Para ello, los estudiantes aprenden reglas gramaticales. El docente es tradicional. Es la autoridad de la clase, los estudiantes hacen lo que el docente les pide. Los estudiantes aprenden a traducir de un idioma a otro. Existe poca iniciativa por parte del estudiante. Así mismo poca interacción entre estudiante-estudiante. Se desarrolla el vocabulario y la gramática junto con la lectura y la escritura. Se presta poca atención al desarrollo de hablar y escuchar.

Método directo. - Este método no es nuevo. Ha sido usado por muchos años. Se volvió muy popular después de que el método de traducción no tuviera éxito en desarrollar la parte comunicacional. La regla básica de este método es que no se permite traducir. El docente hace uso de demostraciones o ayudas visuales sin recurrir al idioma nativo del estudiante. El estudiante es menos pasivo que en el método de traducción. El docente dirige la clase. La relación docente alumno es más de compañeros. La gramática se enseña en forma inductiva; es decir, son los estudiantes quienes deducen las reglas gramaticales. Los estudiantes usan el nuevo vocabulario en oraciones completas. Se enfatiza en el vocabulario sobre la gramática. Sin embargo, las cuatro destrezas se desarrollan por igual.

El método audio lingue.- Lui (2007) dice que el método audio lingue fue el primero en derivarse de la lingüística y psicología. Al igual que el medio directo, este tiene un enfoque 
oral. Los estudiantes llenan espacios en modelos de oraciones gramaticales. A diferencia del método directo, este tiene una sólida base teórica en la lingüística y la psicología. Siguiendo con el análisis de los métodos de aprendizaje del idioma extranjero, el Audiolingüismo es el primer método utilizado para la enseñanza del idioma inglés, utilizado en las fuerzas armadas. Se utilizaba la sustitución de ciertas partes en una estructura base.

También conocido como Método Michigan puesto que Charles Fries (1945) de la Universidad de Michigan lidero la aplicación de principios de lingüística estructural en el desarrollo del método. Se pensaba que para adquirir los modelos de oraciones del idioma de llegada era necesario el condicionamiento; es decir, ayudar a los estudiantes a responder correctamente a través de estímulos.

Método comunicativo. - Nace debido a la necesidad de dominar la comunicación en lugar de dominar estructuras gramaticales bajo la influencia de la lingüística aplicada británica. Este método tiene como objetivo de la enseñanza de un idioma la competencia comunicativa. Supone actividades que involucren comunicación real y tareas significativas. El aprendizaje tiene que ser significativo para que el estudiante apoye el proceso de aprendizaje. Los estudiantes son negociadores y los docentes son organizadores, guías, analistas, consejeros o los que gestionan el proceso de un grupo. Este método ha dominado la enseñanza en muchos países puesto que no solo es interesante, sino que también el estudiante desarrolla competencias lingüísticas y comunicativas. Lui (2007)

Método del silencio. - Aunque muchas personas aprendieron el idioma meta con el método audio lingue, algunos estudiantes no eran capaces de utilizar los hábitos aprendidos en clase fuera de ella. El rol del docente no es censurar sino más bien reforzar la confianza de los estudiantes permitiendo que ellos hagan uso de sus propios recursos. Aunque este método no se deriva del Cognitive Approach comparte algunos principios como por ejemplo la Enseñanza debería estar subordinada al Aprendizaje. Se creía que enseñar significaba servir para el aprendizaje y no dominarlo. Se basa en cómo los bebes y niños adquieren el idioma. (Hernández Reinoso, 2000)

Método de TPR. - Este método fue desarrollado por James Asher. Es el aprendizaje de acciones y respuestas físicas. Se basa en el adelantamiento de la destreza auditiva para aprender a hablar. El docente da instrucciones y los alumnos las realizan hasta que se encuentren listos para ellos den ordenes también. Se desarrollan fases de preparación para la expresión oral en la cual el estudiante hablara cuando se sienta cómodo para hacerlo. Se le considera al estudiante como una persona integral en el que se trata de ayudarlo en crecimiento personal desarrollando valores. (Hernández Reinoso, 2000)

El docente es quien decidirá que método utilizar de acuerdo a las necesidades, tipo de alumnos, contexto que tenga al momento de darse el proceso de enseñanza - aprendizaje.

\section{Aprendizaje}


El aprendizaje de una lengua extranjera es un proceso complejo debido a que el aprendiz debe comprender, además de las estructuras de su primer lenguaje, los principios de la lengua extranjera; dejando atrás las distribuciones mentales propias de su idioma nativo para adoptar aquellas que presenta el nuevo idioma. Es decir, la enseñanza se encarga de guiar y facilitar el aprendizaje, dándole la oportunidad al estudiante de aprender, por medio de estrategias previamente elegidas por el educador para este fin.

La comprensión de cómo el estudiante aprende determina también la filosofía utilizada para enseñar, el estilo de enseñanza y las estrategias didácticas de enseñanza y aprendizaje implementadas en clase, es decir, la didáctica del inglés. Estas estrategias involucran, según Oxford (2006), "etapas y características que queremos estimular en los y las estudiantes para que lleguen a ser mejores estudiantes en la adquisición de una lengua" (p. ix). Aunado a esto y, de acuerdo con Nunan (2003), se puede afirmar que "las estrategias son medios específicos a que los estudiantes recurren para aprender o mejorar su idioma, dependiendo de las tareas y del contexto" (p. 269).

Sin embargo, el desarrollo adecuado de estrategias didácticas depende también del dominio de estas por parte del docente y esto involucra indiscutiblemente su formación académica. Al respecto, Chaves (2008, p. 5) considera que para ofrecer una educación eficiente y eficaz en Costa Rica se debe fortalecer la formación docente. Esta posición es apoyada por Murillo (en Chaves, 2008), al indicar:

El desempeño docente... depende de múltiples factores, sin embargo, en la actualidad hay consenso acerca de que la formación inicial y permanente de docentes es un componente de calidad de primer orden del sistema educativo. No es posible hablar de mejora de la educación sin atender el desarrollo profesional de los maestros. (p. 5)

Chaves (2008) así como Romero y Gómez (2007, p. 5) coinciden en que la formación docente debe contribuir a que los futuros educadores sean conscientes de la influencia que ejercen en los educandos con su actuar, razón por la cual es indispensable que cuestionen constantemente su labor, analicen las relaciones interpersonales que practican y la correspondencia que promueven entre teoría y práctica.

Con base en la posición de estos autores, se puede afirmar que una buena formación docente facilita al educador el desarrollo de la lección. Los aspectos que involucran este proceso, a su vez, posibilitan en el estudiante tener un buen dominio del idioma y de esta manera, desarrollar las destrezas necesarias para utilizar el inglés de manera correcta.

En lo que concierne al proceso de enseñanza y aprendizaje del inglés, si bien es cierto este toma en cuenta una variedad de aspectos, para este trabajo las autoras, como ya se mencionó, ahondarán únicamente en aspectos relacionados con la didáctica, destrezas lingüísticas y comunicativas y estrategias de evaluación, específicamente aspectos que se visualizan dentro de las actividades de apertura y cierre; forma en que el docente presenta el vocabulario, introduce las estructuras gramaticales y explica la materia; orden lógico del desarrollo de las 
destrezas lingüísticas; desarrollo y fortalecimiento de las destrezas comunicativas; uso de recursos tecnológicos o materiales de apoyo; actitud del profesor y colaboración mutua entre docente-estudiante, estudiante-estudiante y estudiante-profesor, y respeto por los estilos de aprendizaje e inteligencias múltiples de los estudiantes

\section{Técnicas pedagógicas}

Dentro de la sociedad, la información se transmite y presenta básicamente a través de medios computarizados, el acceso inmediato a iconos, imágenes, animaciones, voces y sonidos favorece la comprensión de textos, principalmente por su carácter interactivo. Constituyéndose en nuevas técnicas que se apoyan a los docentes para una enseñanza nueva en el accionar pedagógico.

Por otro lado, la legítima renovación de los métodos de enseñanza exige estar sustentada en los principios psicológicos y pedagógicos que justifican la incorporación de las nuevas tecnologías educativas. La Web 2.0 surge en contraste a la web 2.0 ofreciendo posibilidades diferentes a Altavista, correo de Hotmail, encarta o Netscape navigator 4.7. El contenido de la web 2.0 es el resultado de un trabajo colectivo contribuyendo al pensamiento crítico, autonomía, iniciativa, trabajo colabarativo y responsabilidad individual. (Gónzalez Vallés, 2015)

Las formas de conectarse al Internet han ido evolucionando, desde usar en el pasado los teléfonos del hogar, que no era costoso hasta ahora las fibras ópticas, satélites, cable, etc., basándose en la Tecnología, redes sociales, sindicación de contenidos, servicios web y software del servidor (Fernández Martín)

Entre las principales características se puede mencionar que el usuario deja de ser un simple espectador y ahora puede convertirse a través de la web 2.0 en creador y generador de contenidos y servicios. (Nafría, 2008).

Con la Web 2.0 se produce un cambio en la concepción de Internet dejando la representativa unidireccionalidad de sus servicios para pasar a facilitar la máxima interacción de sus usuarios y desarrollar redes sociales en las que el usuario puede expresarse, buscar y recibir información, colaborar y crear conocimiento y compartir contenidos. (Graells, 2005).

\section{Principios de la interactividad}

Las nuevas generaciones de estudiantes universitarios han crecido en un ambiente altamente interactivo, por lo que se espera que el aprendizaje sea interactivo. El aprendizaje en un proceso interactivo en el cual el estudiante desarrolla su comprensión integrando hechos, experiencia y prácticas.

Aparici y Silva (2012) manifiestan que los principios de interactividad son tres:

- Participación-intervención. - no se limita a dar una respuesta positiva o negativa, el usuario interfiere, interviene en el contenido de la información o modifica el mensaje.

- Bidireccional-hibridación. - se refiere a la que la comunicación es la producción de la emisión y la recepción, codificar y decodificar se convierten en un solo elemento. 
- Permutabilidad-potencialidad. - la comunicación supone múltiples redes que se encuentran articuladas con conexiones y la libertad para poder hacer cambios, asociaciones y producir diversos significados

Este autor manifiesta que en base a estos fundamentos el entendimiento de la transmisión pierde su lógica puesto que abre espacios para la participación sensomotora y semántica. Los usuarios no se conforman con tan solo recibir, leer u oír información, sino que desean interactuar, convertirse en sujetos de información. El uso de la interactividad en la enseñanza, requiere compromiso por parte de las universidades, es decir, apoyo a los docentes, infraestructura y evaluación permanente.

\section{Herramientas de la Web 2.0}

Según RAE, las herramientas son un conjunto de instrumentos. Estos pueden ser utilizados para desempeñar un determinado oficio o trabajo. Una herramienta pedagógica es cualquier medio o elemento que interviene en el proceso de enseñanza aprendizaje de los estudiantes. Tienen como fin facilitar y optimizar la calidad de formación. Se las concibe como facilitadores. (Gutiérrez Valderrama, 2011)

Para Valerio (2001) en referencia a las herramientas manifiesta:

"Las herramientas tecnológicas, como cualquier otra herramienta, están diseñadas para facilitar el trabajo y permitir que los recursos sean aplicados eficientemente intercambiando información y conocimiento dentro y fuera de las organizaciones”. (p. 1)

Durante los últimos años la tecnología se ha apoderado de todos los quehaceres del día a día.

A los videojuegos, software, redes sociales, celulares, etc., se los puede denominar como herramientas tecnológicas y han revolucionado el modo en la que las personas viven. Estas herramientas dentro de la educación buscan mejorar la calidad de formación del estudiante.

Las herramientas web tales como blog, wiki, foros, portafolio electrónico, nube, podcast, videoconferencias, correo electrónico, redes sociales, mundos virtuales, páginas personalizadas, lectores de feeds, marcadores sociales, gestión bibliográfica, librerias digitales, repositorio de imágenes, etc., pueden ser usadas en las universidades. (González Vallés, 2014)

En este apartado se puede encontrar aquellas herramientas que fomentan la comunicación, algunas de ellas se describen a continuación:

Redes Sociales: Se puede denominar a las redes sociales como un espacio creado para el intercambio de información y generación de relaciones. Las redes sociales permiten interactuar con otros usuarios a los que se puede o no conocer en la realidad. Permite la interacción a 
través de chats, foros, spaces, etc. Existen diferentes tipos de redes sociales. Por ejemplo, twitter que es un microblogging, linkedin -red social para profesionales, facebook que originalmente fue creada para los estudiantes de la Universidad de Harvard y hoy en es utilizado por cualquier usuario que quiera formar parte ella y de cualquier edad.

Las redes sociales son de un gran atractivo para los que las usan por su aspecto personal y de relación. Mientras mayor el número de usuarios miembros de la red mayor es el atractivo para los alumnos quienes desean estar en contacto permanente con sus compañeros de clases, maestros, amigos, etc. Esto permite generar un ambiente de trabajo favorable.

Según Vera y otros (2009) dicen que "Las redes sociales constituyen un fenómeno clave para entender la dinámica de la sociedad red en la que vivimos".

Entre las redes sociales más usadas se encuentran Facebook y Twitter. También existen redes sociales para profesionales como Linkedin, Academia, Epernicus, Lalisio, ResearchGate, Methodspace, Sciencestage, etc.

\title{
Videoconferencias
}

Chacón (2003) dice sobre la videoconferencia:

\begin{abstract}
"Una videoconferencia es un servicio multimedia que permite la interacción entre distintas personas o grupos de trabajo. Básicamente consiste, en interconectar mediante sesiones interactivas a un número variable de interlocutores, de forma que todos pueden verse y hablar entre sí”. (p. 2)
\end{abstract}

En las videoconferencia, es posible compartir pantalla, usar presentaciones powerpoint fortaleciendo así la interacción. La característica interactiva de las videoconferencias está dirigida a los diferentes estilos de aprendizaje y las necesidades de los jóvenes. El uso de este tipo de herramientas requiere de la motivación de los estudiantes junto con el entusiasmo del docente y el apoyo administrativo.

\section{Plataformas virtuales de aprendizaje}

Los Gestores de Contenido son herramientas software utilizadas para la creación y mantenimiento de sitios web. De los gestores de contenido surgen los sistemas de gestión de aprendizaje (Learning Management System o LMS) conocidos como plataformas de aprendizaje o plataforma e-learning. Facilita la comunicación entre alumnos y profesores por medio de herramientas que permite la gestión de contenidos educativos.

Es un programa software, instalado a un servidor que sirve para administrar, distribuir, y controlar las actividades de formación presencial o e-learning. Existen algunas plataformas de aprendizaje entre ellas: Moodle, Edmodo, Sakai, Blackboard, Dokeos, ATutor, etc. 


\section{La nube}

Se trata de un conjunto de herramientas y servicios a los que se puede acceder únicamente a través de internet. Estas plataformas permiten conectar diferentes dispositivos - como equipos de escritorio, tablets o teléfonos celulares- y aplicaciones informáticas, para acceder a información. Podemos acceder a estos servicios desde cualquier dispositivo. Adicionalmente, toda la información queda guardada sin necesidad de contar con un dispositivo de almacenamiento. Se pueden encontrar servicios de la nube como: YouTube, Gmail, Facebook, Dropbox, SugarSync, Fiabee, Skydrive, Syncro, OpenDrive, Ubunto one, Adrive, Memopal, etc.

\section{Conclusiones}

Se concluye que el impacto que ha provocado las nuevas tecnologías y la Web 2.0 como herramienta metodológica para la enseñanza aprendizaje es un aporte significativo en el desempeño e interactuación con el estudiante, puesto que esto contribuye a la construcción del conocimiento y a la comunicación efectiva.

El Rol del Docente es el factor fundamental para cumplir con los objetivos de enseñanza aprendizaje, puesto que este debe tener el interés, confianza de sus estudiantes para poder manejar la clase de una manera adecuada generando comodidad y entusiasmo al estudiante a la hora de su participación en la clase.

Al revisar los componentes que intervienen en la comprensión lectora se concluye que esta es la base para que los estudiantes desarrollen destrezas que les ayude a ser capaces de realizar inferencias a los textos, tener un razonamiento y una comprensión eficaz.

\section{Referencias Bibliográficas}

Academia.edu. (s.f.). Obtenido de Academia.edu: https://www.academia.edu

Alonso, A. (2006). La competencia intercultural en la enseñanza del inglés dentro. España: Encuentro. Revista de investigación e.

Aparici, R., \& Silva, M. (2012). Pedagogía de la Interactividad. Obtenido de http://www.revistacomunicar.com/pdf/preprint/38/05-PRE-12698.pdf

Arango M., M. L. (2011). Foros virtuales como estrategia de aprendizaje. Obtenido de http://tic.sepdf.gob.mx/micrositio/micrositio2/archivos/ForosVirtuales.pdf

Araníbar Escarcha, N. R. (25 de 04 de 2018). uatf.edu.bo/web_. Obtenido de descargas/publicaciones/LA_LECTURA_Y_LA\%20COMPRENSION_LECTORA.p df: http://www.uatf.edu.bo/web

Banister, S. (2008). Web 2.0 Tools in reading classroom: Teacher exploring literacy in the $21 \mathrm{st}$ century. International Journay of Technology in Teaching and Learning, 109-116. 
Bohórquez Rodríguez, E. (2008). El blog como recurso educativo. Obtenido de EDUTEC: http://edutec.rediris.es/Revelec2/revelec26/articulos_n26_PDF/Edutec-

E_Bohorquez_n26-\%203.pdf

Brown, D. (2000). Principles of Language Learning and Teaching. (4ta. Ed.). Estados Unidos.

Caccuri, V. (2013). Educación con TICS. 179.

Chacón Medina, A. (2003). LA VIDEOCONFERENCIA, CONCEPTUALIZACIÓN, $\begin{array}{lllll}\text { ELEMENTOS } & Y & \text { USO Obtenido de }\end{array}$ http://www.ugr.es/ sevimeco/revistaeticanet/Numero2/Articulos/La\%20videoconfere ncia.pdf

Chaves, L. (2008). Educadoras y educadores inolvidables. . Costa Rica: INIE.

Clark, L. y Starr, L. . (1976). Secondary School Teaching Methods. . Estados Unidos: Mcmillan Publishing Company, Inc.

Crystal, D. (2006). Language and the Internet . Cambridge: Cambridge.

Deans, P. C. (2009). Social Software and Web 2.0 Technology Trends. New York: Information Science Reference.

Espasa, C. (2005). Diccionario de la Lengua Española. Madrid: España.

Fernández Martín, E. (s.f.). Web 2.0. Sindicación de contenidos (RSS). Obtenido de https://ddd.uab.cat/pub/dim/16993748n8/16993748n8a1.pdf

González Vallés, J. E. (2014). Nuevas tendencias en innovación educativa superior. Madrid: ACCI.

Gónzalez Vallés, J. E. (2015). Nuevas tendencias en innovación educativa superior. ACCI.

Graells, P. (2005). La Web 2.0 y sus aplicaciones didácticas. Obtenido de Departamento de Pedagogía Aplicada, Facultad de Educadio UAB: http://www.peremarques.net/web20.htm

Grupo Educare. (2011). Hardware y Software. Obtenido de https://computacioncpc.files.wordpress.com/2011/06/teorc3ada-hardware-ysoftware.pdf

Gutiérrez Valderrama, M. (2011). Influencia de las Herramientas Pedagógicas en el Proceso de Enseñanza del inglés. Obtenido de http://www.funlam.edu.co/uploads/facultadeducacion/51_Influencia-herramientaspedagogicas.pdf

Lauricellaa, S., \& Kayb, R. (2010). Exploring the use of text and instant messaging in higher education classrooms. Obtenido de http://www.researchinlearningtechnology.net/index.php/rlt/article/view/19061

Minguell, M. E. (2002). Interactividad e interacción. Obtenido de file:///C:/Users/Usuario/Downloads/Dialnet-InteractividadEInteraccion-1252603.pdf 
Ministerio de Educación, ITE. (s.f.). Internet Aula Abierta 2.0. Obtenido de http://www.ite.educacion.es/formacion/materiales/157/cd/pdf/modulo_6_2_marcador es_sociales.pdf

Nafría, I. (2008). Web 2.0 El usuario el nuevo rey de internet. España: Ediciones Gestión 2000.

Navarro, D. y Piñeiro, M. . (2008). The Architecture of pedagogy in the Practice Teaching Experience. (PTE) of English as a Foreign Language: A new proposal to evaluate practicum students. : Revista InterSedes, 9(16), 169-187.

Niño, J. (2010). Aplicaciones Web 2.0 (Aplicaciones web). Editex.

Palomar Sánchez, M. J. (2009). Innovación y Experiencias Educativa. Obtenido de Ventajas e inconvenientes de las TICS en el aula: http://www.csicsif.es/andalucia/modules/mod_ense/revista/pdf/Numero_25/MARIA_JOSE_PALO MAR_SANCHEZ01.pdf

Pérez Vera, C. y. (2009). La Web 2.0 como recurso para la enseñanzael francés como lengua extranjera. Madrid: Ministerio de Educación, Cultura y Deporte.

Prato, L. B., \& Villoria, L. (2010). Aplicaciones Web 2.0 - Redes sociales. Córdoba: Universidad Nacional de Villa María.

Quintanilla, E. A., \& Ferreira Cabrera, A. (2010). Habilidades Comunicativas en L2 mediatizadas por la Tecnología en el Contexto de los Enfoques por tareas y cooperativo. Estudios Pedagógicos Valdivia, 213 - 231.

Sarmiento Santana, M. (2007). Medios, Recursos, Materiales Multimedia. Obtenido de http://www.tdx.cat/bitstream/handle/10803/8927/F-

TESIS_CAPITULO_4.pdf?sequence $=6$

Sharma, P., \& Barrett, B. (2010). Blended Learning: Using Technology in and beyond the classroom. Obtenido de https://www.researchgate.net/publication/220374249_Blended_Learning_Using_Tech nology_in_and_beyond_the_Language_Classroom

Shelly, G. B., \& Frydenberg, M. (2010). Web 2.0: Concepts and Applications. Boston.

Valerio, G. (2001). Transferencia. Obtenido de Revista Digital de Postgrado, Investigación y Extensión del Campus Monterrey: www.mty.itesm.mx/die/ddre/transferencia/57/57III.01.html 
Para citar el artículo indexado.

Colcha Guashpa, E., Herrera Andrade, Z., Barragán Murillo, R. de los Ángeles, \& Guano, D. (2019). La Comprensión Lectora de textos técnicos del idioma inglés para el aprendizaje mediante el uso de $\begin{array}{llll}\text { técnicas } \quad \text { pedagógicas. } & \text { Explorador } & \text { 134-155. }\end{array}$ https://doi.org/10.33262/exploradordigital.v3i3.848

\section{Ciencia \\ LDigital}

El artículo que se publica es de exclusiva responsabilidad de los autores y no necesariamente reflejan el pensamiento de la Revista Explorador Digital.

El articulo queda en propiedad de la revista y, por tanto, su publicación parcial y/o total en otro medio tiene que ser autorizado por el director o editor de la Revista Explorador Digital.
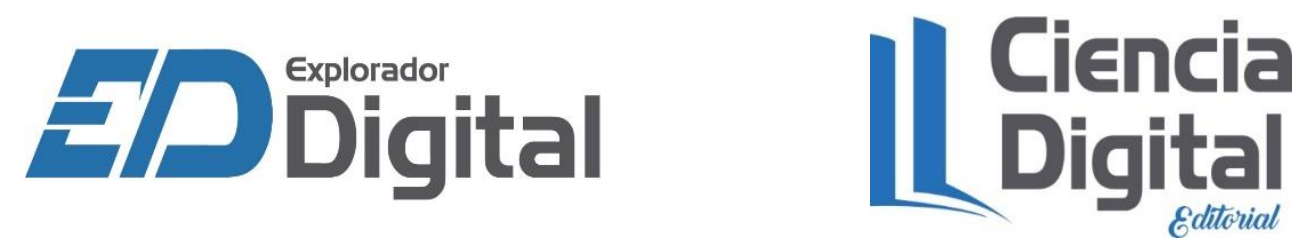